\section{Arteritis de células gigantes: actualización y proposición de un algoritmo de estudio}

\author{
VERÓNICA WOLFF C. ${ }^{1}$, PAOLA PAOLINELLI G. ${ }^{2}$, \\ DAVID LADRÓN DE GUEVARA H. ${ }^{2}$
}

\section{An update on giant cell arteritis}

Giant cell arteritis (GCA) is a primary granulomatous systemic vasculitis involving the aorta and its main branches that affects people aged over 50 years with a genetic predisposition. Its main phenotypes are cranial and extracranial involvement, with or without symptoms of polymyalgia rheumatica. These phenotypes can overlap. The extracranial form can be oligosymptomatic and must be sought directly. The main complications of the disease are ischemia of essential territories such as the optic nerve or cerebral circulation, and aneurysmal dilations of the aorta and its large branches. Clinicians must be aware of all the presentation forms of the disease, to start a timely treatment and avoid potentially serious or fatal consequences. To date, the diagnosis of GCA is based on clinical and pathological criteria, with the temporal artery biopsy as the "gold standard" for diagnosis, although its sensitivity is variable. This can lead to an underdiagnosis in patients with negative biopsies or predominant extra-cranial symptoms. The emergence of new and valuable imaging tools substantially improved the timely diagnosis, mainly in subclinical and oligosymptomatic forms. Among them we highlight ultrasonography of the temporal and axillary arteries, Computed Tomography Angiography, Magnetic Resonance Angiography, and PET-CT. These imaging techniques are complementary, and their use is highly recommended. GCA treatment is based on steroidal therapy, often associated with a corticosteroid-sparing immunosuppressive agent. The follow-up is eminently clinical.

(Rev Med Chile 2020; 148: 1619-1629)

Key words: Giant Cell Arteritis; Multidetector Computed Tomography; Positron-Emission Tomography; Ultrasonography.
'Departamento de Medicina Interna, Unidad de Reumatología Clínica Las Condes. Santiago, Chile.

${ }^{2}$ Departamento de Radiología, Clínica Las Condes. Santiago, Chile.

Trabajo no recibió financiamiento. Los autores declaran no tener conflictos de interés.

Recibido el 1 de septiembre de 2019, aceptado el 24 de junio de 2020.

Correspondencia a:

Dr. David Ladrón de Guevara H. Servicio de Radiología, Clínica Las Condes. Santiago, Chile. dlg@clc.cl
L a arteritis de células gigantes (ACG) es una vasculitis sistémica granulomatosa, primaria $\checkmark$ e idiopática que involucra arterias medianas $y$ grandes en mayores de 50 años ${ }^{1}$.

La forma clínica más conocida es la variante que compromete las ramas craneanas de la aorta, principalmente la arteria temporal ("arteritis de la temporal”). Sin embargo, en los últimos años se ha reconocido que la ACG comprende un espectro de fenotipos entre los que encontramos, además de la vasculitis craneana, la polimialgia reumática
(PMR) y la variante "extra-craneana" (VEC) o de vasos grandes, que compromete la aorta y sus ramas principales. Estos 3 fenotipos pueden manifestarse en forma aislada o superponerse entre sí ${ }^{2}$.

Fisiopatológicamente, el fenómeno inflamatorio se inicia por activación inapropiada de las células dendríticas en la adventicia de los vasos, las que activan a células TCD4 (+) y macrófagos ${ }^{3}$.

Para evitar las graves consecuencias clínicas que pueden ocurrir en esta patología es fundamental un diagnóstico oportuno e inicio precoz 
del tratamiento. Por ello, en este artículo hemos querido resaltar la importancia de reconocer las formas menos conocidas de esta enfermedad, principalmente la VEC, y las herramientas diagnósticas disponibles en la actualidad.

El tratamiento de la ACG escapa al foco principal de nuestra revisión, por lo que no será analizado en profundidad.

\section{Epidemiología y cuadro clínico}

La ACG es la vasculitis primaria más frecuente en mayores de 50 años, con una incidencia anual estimada entre 1,6 a 32,8 casos x 100.000 hab/año en estudios en países de Europa, Estados Unidos, Israel y Oceanía ${ }^{4}$. La mayor prevalencia se ha observado en personas de herencia escandinava, y hay evidencia de alguna asociación genética con HLA-DRB1 ${ }^{\star} 04^{5}$. Es importante recalcar que la prevalencia e incidencias reales no se conocen del todo, ya que los principales estudios epidemiológicos se han focalizado en pacientes con síntomas craneanos predominantes, lo que limita la estimación real de la VEC.

Las manifestaciones clínicas dependen del fenotipo predominante (Tabla 1). En la variante craneana destaca la cefalea temporal, sensibilidad del cuero cabelludo, disminución de pulsos en las arterias temporales, claudicación mandibular o de la lengua y trastornos visuales incluyendo amaurosis fúgax, hasta pérdida completa e irreversible de la visión, entre otros. La causa subyacente a la pérdida visual es una neuritis óptica isquémica secundaria a arteritis de las arterias ciliares posteriores que irrigan la cabeza del nervio óptico y/o por isquemia de la arteria central de la retina ${ }^{3}$. El compromiso visual suele ser agudo y unilateral inicialmente. Sin tratamiento oportuno puede hacerse irreversible, y con un riesgo de más de 50\% de extenderse al lado contralateral ${ }^{3,6}$.

En relación al fenotipo extra-craneano, el compromiso inflamatorio de la aorta y sus grandes ramas puede ser silente y manifestarse sólo con síntomas constitucionales y polimiálgicos. Cuando es sintomático, predominan síntomas derivados de la estenosis vascular como soplos arteriales, claudicación de extremidades y diferencia de pulsos distales. Una de las graves complicaciones de esta variante, secundaria a la inflamación vascular, son los aneurismas principalmente de la aorta, con riesgo de disección y/o rotura ${ }^{7}$.

Los síntomas de PMR incluyen dolor y rigidez de cintura escapular y/o pélvica, y se pueden observar en 40-60\% de los pacientes con ACG en el momento del diagnóstico, tanto en la variante craneana como extra-craneana. En los casos de PMR aislada, hasta 15-20\% de los pacientes pue-

Tabla 1. Fenotipos de presentación espectro ACG y PMR

\begin{tabular}{|c|c|c|c|}
\hline Síntomas y signos & $\begin{array}{c}\text { ACG } \\
\text { craneana }\end{array}$ & $\begin{array}{c}\text { ACG } \\
\text { extra-craneana }\end{array}$ & PMR \\
\hline Cefalea & ++ & - & - \\
\hline Sensibilidad en el cuero cabelludo & ++ & - & - \\
\hline Claudicación mandibular - lingual & ++ & - & - \\
\hline Trastornos visuales & ++ & - & - \\
\hline Síntomas constitucionales (fiebre, baja de peso, etc.) & + & ++ & ++ \\
\hline Soplos arteriales / Disminución de pulsos & + & ++ & - \\
\hline Claudicación de extremidades & - & ++ & - \\
\hline Dolor y rigidez cintura escapular y/o pélvica & + & ++ & ++ \\
\hline Aumento de reactantes de fase aguda & ++ & ++ & ++ \\
\hline Artritis periférica -Sd. RS3PE* & + & + & ++ \\
\hline
\end{tabular}

*Sd. RS3PE: "Remitting seronegative symetic synovitis with pitting edema" (Sinovitis simétrica seronegativa, remitente y con edema). 
den desarrollar ACG, particularmente si se dejan sin tratamiento ${ }^{3}$.

Síntomas sistémicos como baja de peso, fiebre y elevación de parámetros inflamatorios (VHS, PCR, trombocitosis) son frecuentes y pueden estar presentes en todos los fenotipos ${ }^{3,8,9}$.

\section{Diagnóstico}

Los criterios internacionales de clasificación (ACR) aún vigentes para $A_{C G}{ }^{10}$ incluyen 5 variables, 4 de las cuales son síntomas craneanos y una es el resultado de la biopsia de las arterias temporales (BAT), la cual aún es considerada formalmente el "gold-standard" para el diagnóstico. Los hallazgos histológicos clásicos incluyen inflamación granulomatosa de la pared arterial, fragmentación de la lámina elástica interna y engrosamiento de la íntima ${ }^{2,3}$. La sensibilidad de la BAT varía entre $24 \%$ y $94 \%$ en distintas cohortes, dependiendo del grupo de pacientes seleccionados para el procedimiento ${ }^{4} \mathrm{y}$ del tiempo transcurrido entre el inicio de la terapia esteroidal y la BAT, que no debiera superar las 2-4 semanas para mantener una sensibilidad aceptable ${ }^{11}$. Entre los factores clínicos predictores de BAT positiva están la mayor edad, claudicación mandibular, síntomas visuales, trombocitosis y proteína $\mathrm{C}$ reactiva ${ }^{11}$. En caso que la BAT inicial resultara negativa y persistiera una alta sospecha clínica, se podría realizar una BAT contralateral, lo que debe ser analizado caso a caso ${ }^{8}$.

Aunque estos criterios clínicos e histológicos están diseñados para clasificar pacientes en un grupo homogéneo, y no con un objetivo diagnóstico, resulta evidente que los síntomas y hallazgos de la variante extra-craneana están subrepresentados. Por lo anterior, si se buscan exclusivamente síntomas craneanos y se confía solo en la BAT como medio de llegar al diagnóstico, muchos pacientes con ACG podrían no ser diagnosticados ni tratados oportunamente, ya que en la mayoría de los casos de ACG extra-craneana no es factible obtener una muestra para biopsia, salvo en complicaciones como disección y/o rotura de aneurismas de la aorta que requieran tratamiento quirúrgico. En esa línea, la actualización de las recomendaciones EULAR para el manejo de las vasculitis de vaso grande acepta que el diagnóstico sea hecho con imágenes y no necesariamente con $\mathrm{BAT}^{12}$.

\section{Imágenes en el diagnóstico de la ACG}

En los últimos años se han incorporado importantes técnicas de imágenes que permiten un diagnóstico oportuno tanto de la variante craneana como extra-craneana, incluyendo formas silentes o subclínicas de esta última.

La angiografía por tomografía computada (Angio-TC), la angiografía por resonancia magnética (Angio-RM), la tomografía por emisión de positrones-tomografía computada (PET-CT) usando F18-fluorodeoxiglucosa (F18-FDG) y el ultrasonido doppler color (USDC), además de ser técnicas no invasivas, algunas de ellas como el USDC han demostrado incluso un mejor rendimiento diagnóstico que la BAT ${ }^{9,13,14}$.

\section{Ultrasonido Doppler color}

El USDC es una técnica de imagen importante para el diagnóstico precoz de la ACG craneal ${ }^{9}$. La evaluación de la pared y lumen de las arterias temporales y axilares en tiempo real permite pesquisar el compromiso de los vasos craneanos y/o extra-craneanos ${ }^{15,16}$.

Las arterias temporales normales poseen una pared fina y se colapsan con la presión del transductor (Figura 1). Un engrosamiento patológico de la pared no permite una compresión completa del vaso, considerándose positivo si el colapso de éste es parcial o ausente (Figura 2).

El mayor espesor de la pared es secundario a edema e infiltración celular, determinando el llamado "signo del halo" (Figura 2), uno de los hallazgos ultrasonográficos más característicos de la enfermedad. También se puede encontrar estenosis, oclusión y aneurismas (Figura 3).

El "signo del halo" se describe como un engrosamiento concéntrico e hipoecogénico de la pared de la arteria temporal. Un espesor mayor de 0,7 $\mathrm{mm}$ se considera altamente predictor de $\mathrm{ACG}^{17,18}$. Para la arteria axilar un valor mayor de $1,5 \mathrm{~mm}$ es diagnóstico de vasculitis ${ }^{19}$.

Una revisión sistemática de la literatura realizada en 2017 por Duftner et al. ${ }^{20}$, mostró para el "signo del halo" una sensibilidad de 77\% (IC 95\%, 62\%-87\%) y especificidad de 96\% (IC 95\%, 88\%-99\%). El rendimiento aumenta cuando el compromiso es bilateral ${ }^{21}$. En un estudio de 87 pacientes con sospecha de ACG, Croft et al describen una sensibilidad de $81 \%$, especificidad de 98\%, valor predictivo positivo (VPP) de 97\% y 

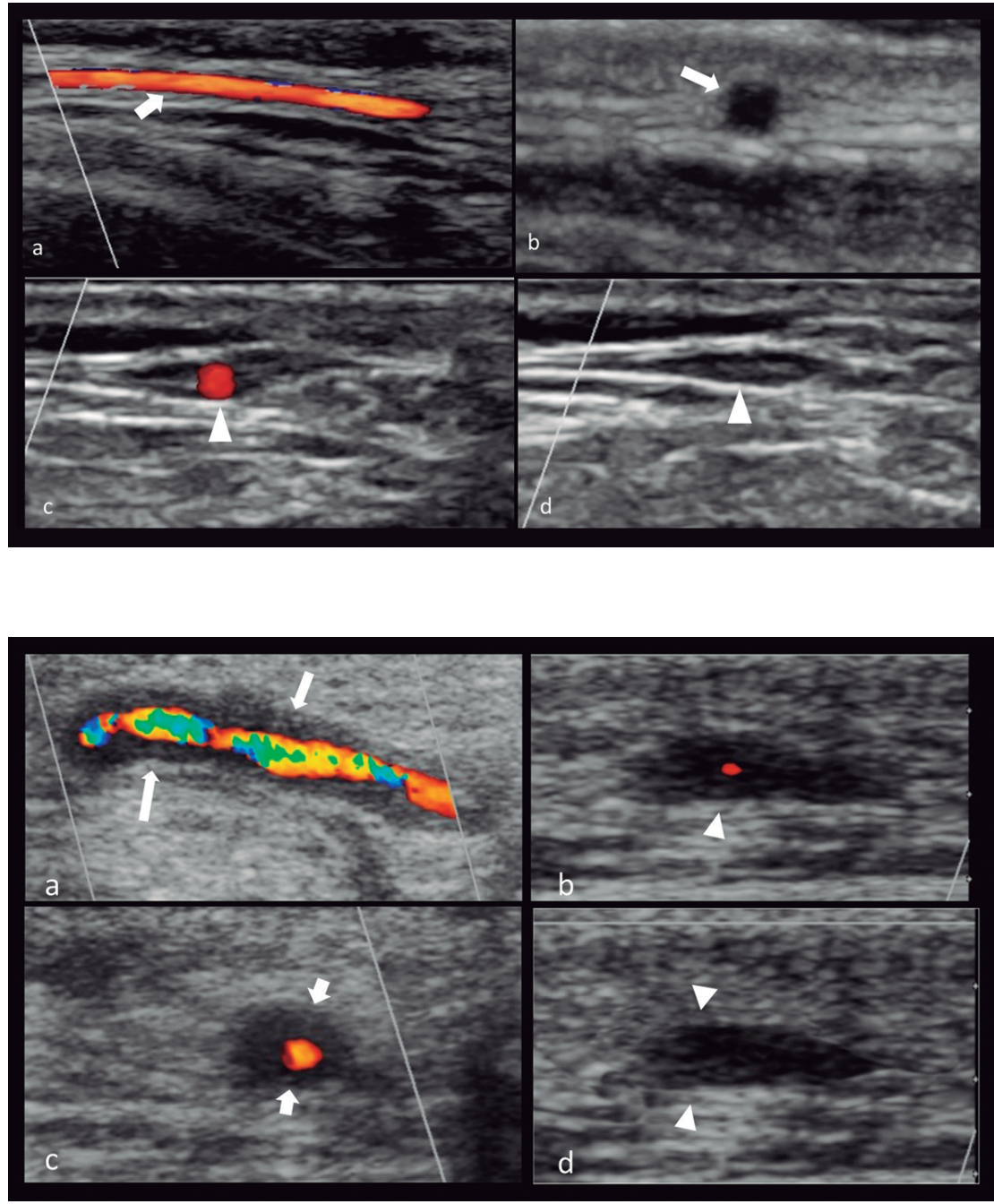

Figura 2. Doppler color de paciente con ACG craneana vista longitudinal (a) y axial (c) de arteria temporal, muestran engrosamiento parietal hipoecogenico (signo del halo) $>0,7 \mathrm{~mm}$ (flechas); (b, d) falta de compresión con la presión del transductor (punta de flecha).
Figura 1. US Doppler color de arteria temporal normal: (a) vista longitudinal en color (b) axial en escala de grises, cia sencia de halo hipoecogénico (flechas); (c) Corte axial en co(a) este aparece completamente (d) (punta de flecha).

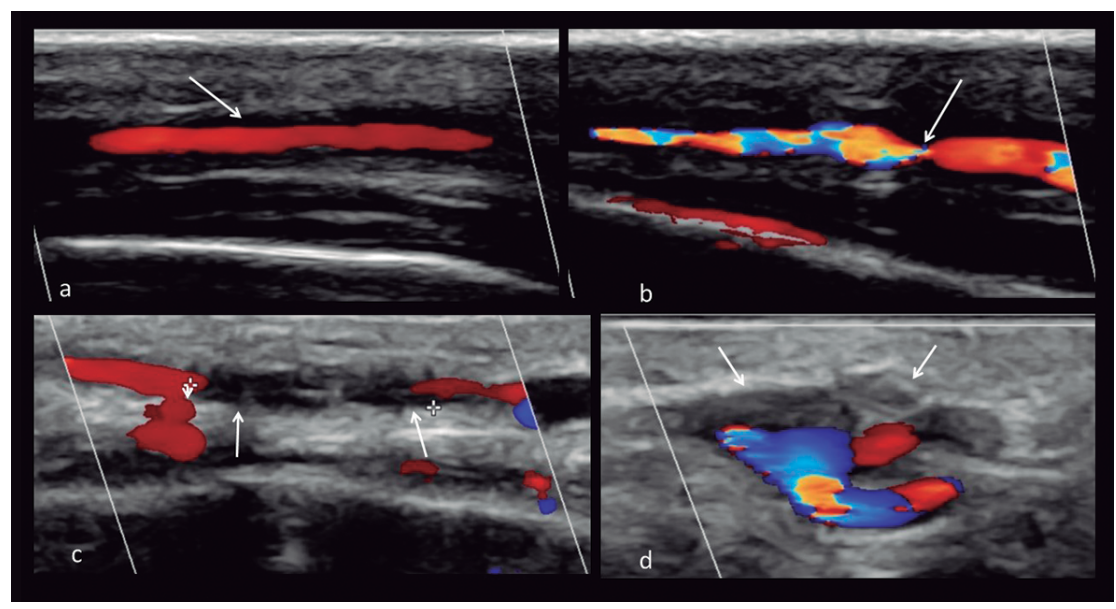

Figura 3. Hallazgos al Doppler color de arterias temporales en diferentes pacientes con ACG comprobada: (a) engrosamiento parietal hipoecogénico (flecha); (b) estenosis del segmento mas comprometido (flecha); (c) segmento ocluído; (d) aneurisma parcialmente trombosado del tronco de la temporal. 
valor predictivo negativo (VPN) de $88 \%$ para el Doppler color ${ }^{22}$.

A diferencia del halo, las alteraciones del lumen como estenosis u oclusión tienen menor sensibilidad y especificidad, ya que se sobreponen con otras patologías como la ateromatosis.

No existe un consenso respecto al tiempo que tardan en regresar las alteraciones después de iniciado el tratamiento. En un estudio prospectivo de 30 pacientes realizado el año 2012, De Miguel et $\mathrm{al}^{23}$ registraron desaparición del halo en $95 \%$ de los pacientes, de los cuales $50 \%$ lo hizo dentro de las 8 semanas de iniciado el tratamiento (promedio 11 semanas). En 2012 Hauenstein et $\mathrm{al}^{24}$, demostraron una disminución de la sensibilidad del USDC para detección de ACG desde $92 \%$ al inicio del tratamiento, a 50\% sobre los 4 días. El estudio multicéntrico TABUL (Temporal Artery Biopsy v/s US in diagnosis of GCA $)^{14}$, mostró una rápida disminución del halo, especialmente después de 4 días de tratamiento con corticoides, coincidiendo con la disminución de los síntomas. Por estas observaciones, la guía EULAR $2018^{9}$ recomienda que para un mejor rendimiento del USDC, el primer estudio diagnóstico debe realizarse antes de la primera semana de tratamiento esteroidal. La pared de la arteria axilar puede persistir engrosada por años y el seguimiento a largo plazo busca detectar las complicaciones como aneurismas y estenosis.

La utilidad del USDC para guiar la BAT es controversial. Mientras un estudio mostró aumento de la sensibilidad de la biopsia eco guiada ${ }^{21}$, Germano et al, en $2015^{25}$ encontró que el USDC no mejoraba la sensibilidad de ésta.

Dada su buena sensibilidad y especificidad en manos de un operador entrenado, y por tratarse de una técnica no invasiva y de bajo costo, el USDC ha sido incluido en la fase inicial del diagnóstico precoz de la ACG, especialmente en la variante craneana ${ }^{9}$. Algunos autores como Schmidt et $\mathrm{al}^{17}$ en 1997, mostraron que un USDC positivo realizado por un operador calificado podría reemplazar la BAT. Esto ha sido ha sido ratificado en investigaciones posteriores ${ }^{21,25,26}$.

\section{Tomografía computada con técnica angiográfica}

La Angio-TC es útil para el estudio de la aortitis, la que está presente en más de $50 \%$ de las $\mathrm{ACG}^{27}$, y de sus complicaciones, particularmente aneurismas y estenosis. El hallazgo característico a la AngioTC es el engrosamiento de la pared vascular $^{20}$. El AngioTC posee una sensibilidad de $73,3 \%$, especificidad de $84,6 \%$, VPN de $64,6 \%$ y VPP de $84,6 \%$ en el diagnóstico de aortitis basado exclusivamente en el engrosamiento parietal ${ }^{27}$.

\section{Resonancia magnética}

Las ventajas de la RM y Angio-RM radican en su alta resolución de contraste, capacidad de realizar estudios angiográficos aún sin utilizar medio de contraste, y a que no utiliza radiación ionizante $^{28}$. Diversas series han mostrado alto rendimiento de la Angio-RM en el estudio del compromiso vascular en arterias superficiales del cráneo, permitiendo evaluar, además del engrosamiento de la pared vascular, su grado de inflamación y la existencia de edema perivascular ${ }^{20}$. En un metaanálisis reciente, Duftner et $\mathrm{a}^{20}$ selecciona publicaciones centradas en el compromiso de arterias temporales y occipitales demostrados con RM, basándose tanto en el engrosamiento como en el realce de las paredes vasculares, con una sensibilidad de $73 \%$ (IC $95 \%, 57 \%$ a $85 \%$ ), especificidad de $88 \%$ (IC $95 \%, 81 \%$ a $92 \%$ ) para ACG diagnosticada clínicamente, y 93\% (IC 95\%, $89 \%$ a $96 \%$ ) y $81 \%$ (IC $95 \%, 73 \%$ a $87 \%$ ) para ACG con biopsia positiva, respectivamente. Ellos no encontraron estudios referentes al valor de la RM en evaluación de arterias extra-craneanas.

En un estudio multicéntrico de 185 pacientes con ACG, Klink et $\mathrm{al}^{28}$ obtuvieron una sensibilidad de $88,7 \%$, especificidad de $75,0 \%$, VPP de $85,9 \%$ y VPN de $79,4 \%$ en la evaluación de arterias superficiales craneales en pacientes con ACG corroborada por BAT, demostrando compromiso vascular bilateral en $56 \%$ de los casos. Ellos describen una disminución significativa de los signos de vasculitis luego del $5^{\circ}$ día de iniciada la terapia corticoidea.

Aunque la Angio-RM es una técnica útil en el estudio de ACG craneana, no hay evidencia suficiente que apoye su uso en ACG extra-craneana'. En las guías de consenso EULAR ${ }^{9}$ sobre el estudio de vasculitis de grandes vasos se menciona la potencial utilidad de protocolos de Angio-RM que incluyan territorios vasculares desde la bifurcación carotídea hasta la bifurcación de arterias iliacas, sin embargo, la evidencia sustenta el uso de RM sólo en aortitis asociada a Enfermedad de Takayasu, y no así en aortitis por ACG, por lo que su uso rutinario en ACG extra-craneana no es recomendado?. 


\section{PET/CT F18-FDG}

Al ser una técnica híbrida, el PET/CT proporciona información funcional, no disponible con las técnicas de radiología convencional ${ }^{29}$. El radiotrazador más utilizado es la F18-FDG, que da cuenta de la inflamación asociada al proceso vasculítico. Mientras mayor cantidad de células inflamatorias reclute el vaso, mayor captación de F18-FDG mostrará. Las células sanguíneas que más glucosa consumen son los leucocitos, los que suelen infiltrar las zonas inflamatorias cualquiera sea su naturaleza, infecciosa o no infecciosa. Por este motivo, el PET/CT mostrará hipercaptación en cualquier tipo de vasculitis de grandes vasos, $y$ aún en ateromatosis inflamatoria, lo que disminuye la especificidad del método ${ }^{29}$. La adecuada selección de los pacientes a estudiar y el uso de técnicas de cuantificación como el SUVmax (Standarized uptake value máximum) ayudan a optimizar el rendimiento del examen ${ }^{27,29}$, alcanzando cifras de especificidad y valor predictivo positivo de $100 \%{ }^{27}$. Si bien la resolución espacial de los equipos PET antiguos no permitía visualizar arterias pequeñas, los equipos actuales con resoluciones de $3 \mathrm{~mm}$ en adelante, han hecho posible aumentar la sensibilidad en el compromiso de arterias temporales, vasos carotídeos y vertebrales extra-craneanos ${ }^{29}$. Hay que tener presente que el PET/CT no es útil en la evaluación del compromiso vascular intracraneano, dada la alta concentración fisiológica de F18-FDG en el encéfalo, que enmascara la captación de los pequeños vasos intracraneanos.

La ACG puede asociarse a PMR en 40-60\% de los $\operatorname{casos}^{6,30}$. El PET/CT ayudaría a reconocer también esta entidad, mostrando un patrón de hipercaptación típico a nivel periarticular en hombros, articulaciones esterno-claviculares y caderas, en sitios de inserción musculo-tendínea de tuberosidades isquiáticas y trocánteres femorales, $y$ en ligamentos interespinosos de la columna ${ }^{31,32}$ (Figura 4).

Una característica importante del PET/CT es la habilidad de revelar hipermetabolismo glucídico antes de los cambios morfológicos ocurran, lo que permite un diagnóstico más precoz $^{29}$ (Figuras 5 y 6 ).

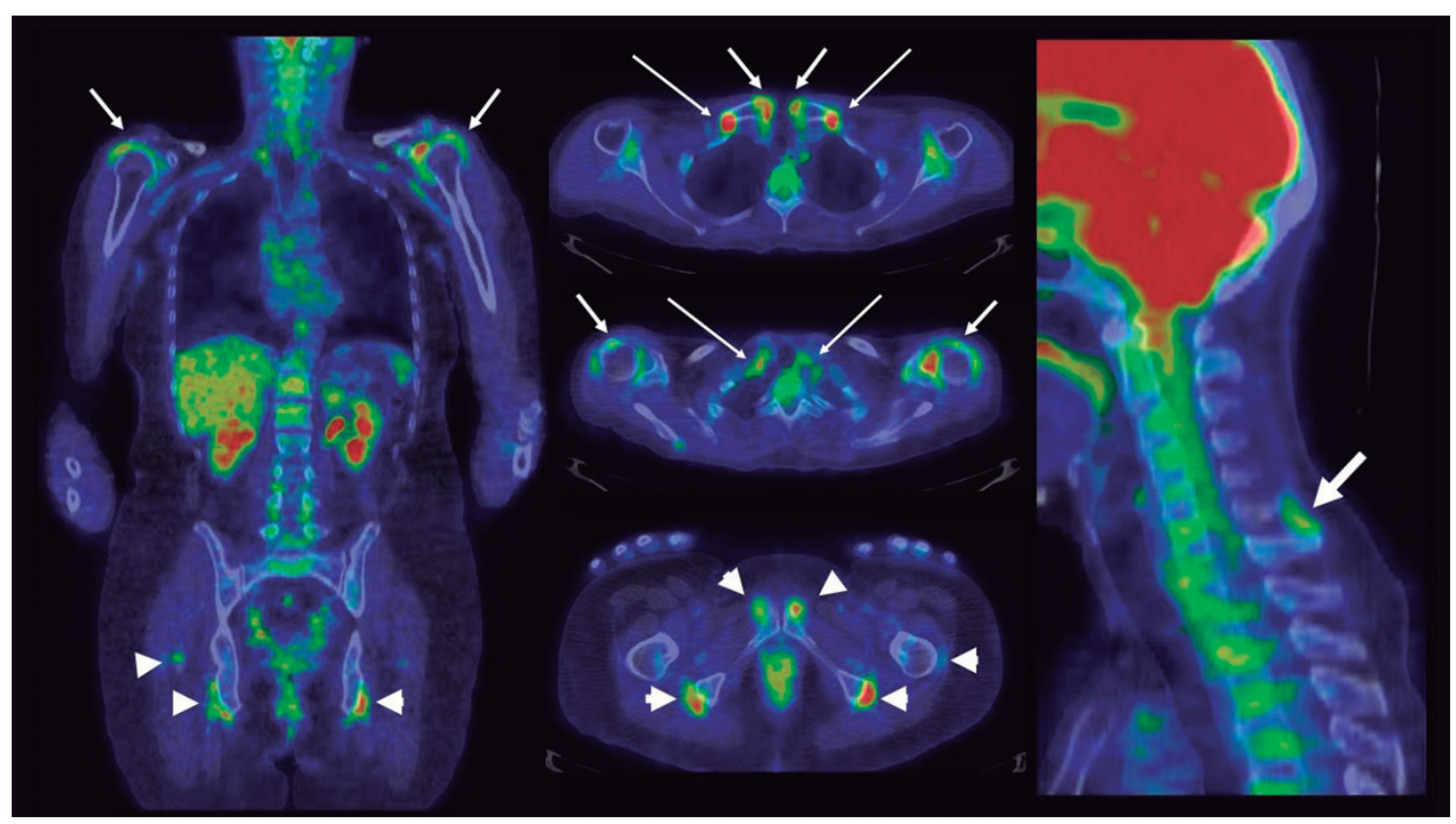

Figura 4. Paciente con Polimialgia Reumática con hallazgos característicos al PET/CT: hipercaptación periarticular en hombros y uniones acromioclaviculares (flechas cortas), en relación a ligamentos costoclaviculares (flechas largas), en bursas peritrocanteras, isquiáticas y pubianas (cabeza de flechas), y en el complejo ligamentoso posterior de la columna (flecha gruesa). En la imagen de la izquierda se observa además compromiso vascular en eje subclavio-axilar a ambos lados y en aorta ascendente, compatible con asociación de PMR y ACG. 
Arteritis de células gigantes: algoritmo de estudio - V. Wolff et al

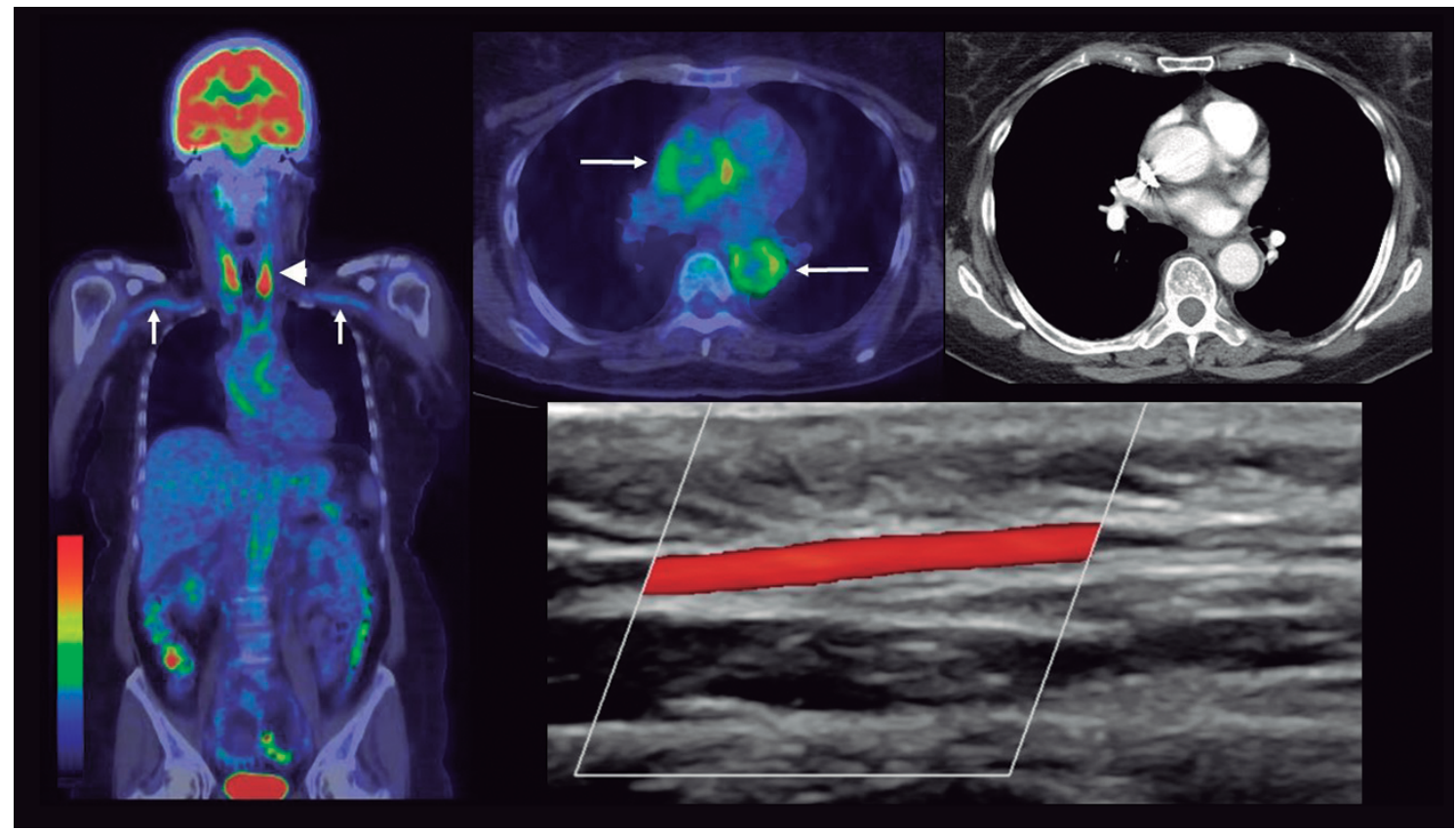

Figura 5. Paciente con fenotipo extra-craneano. Marcada hipercaptación parietal difusa de F18-FDG en aorta torácica (flechas largas), con AngioTC que no muestra engrosamiento parietal aórtico. Moderada captación en eje arterial subclavio-axilar bilateral (flechas cortas). Esta paciente con ACG también presentaba una hipercaptación tiroidea difusa (cabeza de flecha) compatible con tiroiditis. Abajo a la derecha: ecografía Doppler color de arteria temporal sin alteraciones.

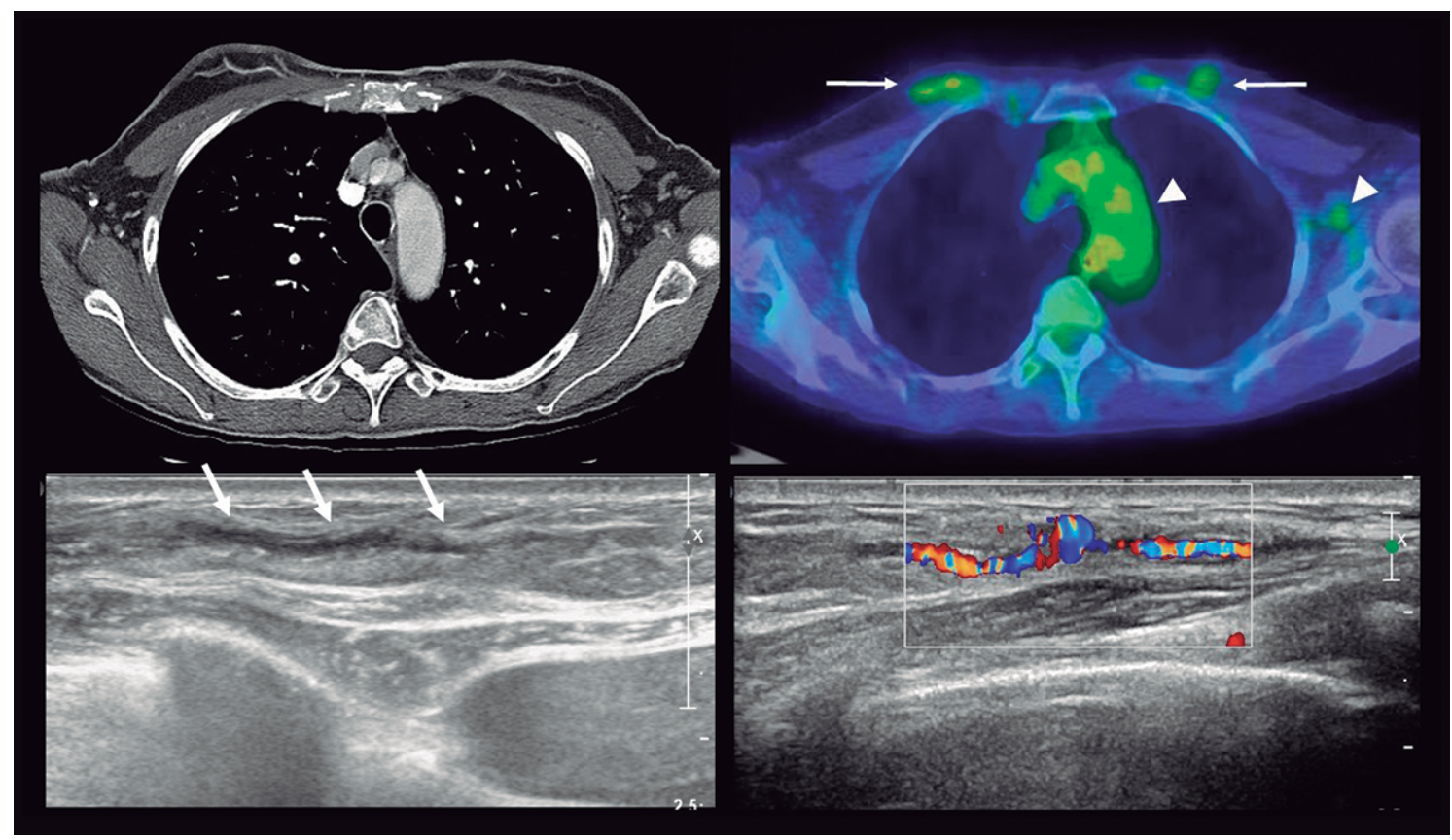

Figura 6. Paciente con ACG y compromiso bilateral de arterias perforantes internas (flechas), las que muestran intensa hipercaptación de F18-FDG en forma bilateral. También se ve captación anormal en arteria axilar izquierda y en cayado aórtico (cabezas de flecha). En las imágenes inferiores se exhibe la Ecografía Doppler Color de arterias perforantes internas con engrosamiento parietal irregular (flechas), aunque permeables. 
Solo la mitad de los PET/CT con hipercaptación aórtica en pacientes con síndromes inflamatorios prolongados tendrá una biopsia de arteria temporal positiva ${ }^{33}$. Esto puede ser explicado por al menos dos situaciones:

1) la tasa de falsos negativos de la BAT, que es de $15-75 \%{ }^{20,28,32}$ y que en parte corresponderían a casos de presentación exclusiva extra-craneana sin compromiso real de arterias temporales (Figura 5);

2) debido a que la hipercaptación vascular de FDG es inespecífica, y puede deberse también a inflamación de naturaleza infecciosa o ateromatosa. En este sentido, la VHS elevada puede aumentar el valor predicitvo positivo de un PET/CT alterado ${ }^{33}$. Por otro lado, la visualización por TC de placas de ateroma coincidente a las zonas de hipercaptación vascular hace sospechar que se trate más bien de una causa ateromatosa.

En una serie estudiada con PET/CT y AngioTC, Lariviere et $\mathrm{al}^{27}$ utilizan el índice SUVmax para establecer el diagnóstico, con una sensibilidad de $66,7 \%$, especificidad de $100 \%$, VPN de $64,3 \%$ y VPP de $100 \%$. El promedio de SUVmax obtenido en población con ACG fue de 4,1 (rango: 2,8-5,8). Ellos demuestran el valor incremental del estudio metabólico, ya que la gran mayoría de los vasos engrosados al AngioTC presentan hipercaptación al PET/CT, pero sólo 37\% de los vasos hipercaptantes de F18-FDG mostraban engrosamiento parietal.

Por todo lo anteriormente mencionado, el PET/CT se ha convertido en una técnica ampliamente recomendada para el diagnóstico de ACG, especialmente en busca de fases precoces de la enfermedad ${ }^{29}$.

\section{Diagnóstico diferencial}

Entre los diagnósticos diferenciales más importantes de ACG/PMR encontramos otras causas de aortitis (infecciosas, enfermedad relacionada a IgG4, enfermedad ateromatosa, etc.), otras vasculitis sistémicas, especialmente Takayasu, vasculitis asociadas a ANCA, y poliarteritis nodosa; y otras enfermedades reumatológicas sistémicas, en particular la artritis reumatoide de inicio tardío. En relación al USDC y PET/CT, también se debe considerar la ateromatosis.

\section{Tratamiento}

Dado las potenciales complicaciones asociadas a esta vasculitis, ante la sospecha clínica, el paciente debe ser referido precozmente al especialista, para la confirmación diagnóstica e inicio precoz del tratamiento (fast track $)^{34}$.

El eje terapéutico principal son los corticoesteroides sistémicos (CS), normalmente asociados a algún inmunosupresor como metotrexato o drogas biológicas como el inhibidor de interleukina 6 tocilizumab. Esto permite ahorrar CS dado su amplio perfil de efectos adversos.

El análisis detallado de las estrategias terapéuticas disponibles escapa al propósito de este artículo.

\section{Seguimiento}

El seguimiento de la ACG/PMR se debe realizar principalmente en base a parámetros clínicos y de laboratorio (especialmente los reactantes de fase aguda). La utilidad de las imágenes en el seguimiento es controversial, y no está claro el valor real de la persistencia de signos inflamatorios en imágenes como AngioTC o PET-CT e incluso en USDC en pacientes clínicamente inactivos ${ }^{35}$. Por ello, a la fecha se recomienda que el seguimiento con imágenes sea utilizado principalmente para descartar complicaciones que pueden ser tardías, como estenosis, oclusión o aneurismas. La elección del método de imagen a utilizar debe ser realizado en base a cada caso particular, considerando la situación clínica, disponibilidad del método diagnóstico y experiencia del operador'.

\section{Conclusión}

La ACG comprende un espectro fenotípico que incluye síntomas polimiálgicos, compromiso de las ramas craneanas de la aorta y compromiso extra-craneano. Este último puede ser subclínico y con mucha frecuencia subdiagnosticado ${ }^{34}$, lo que retrasa el inicio oportuno del tratamiento.

Actualmente existen nuevas y valiosas técnicas de imágenes que aportan en el diagnóstico precoz e incluso podrían llegar a reemplazar a la BAT, especialmente en aquellos pacientes sin compromiso craneano. En este sentido, varios grupos han diseñado algoritmos para el diagnóstico precoz de 


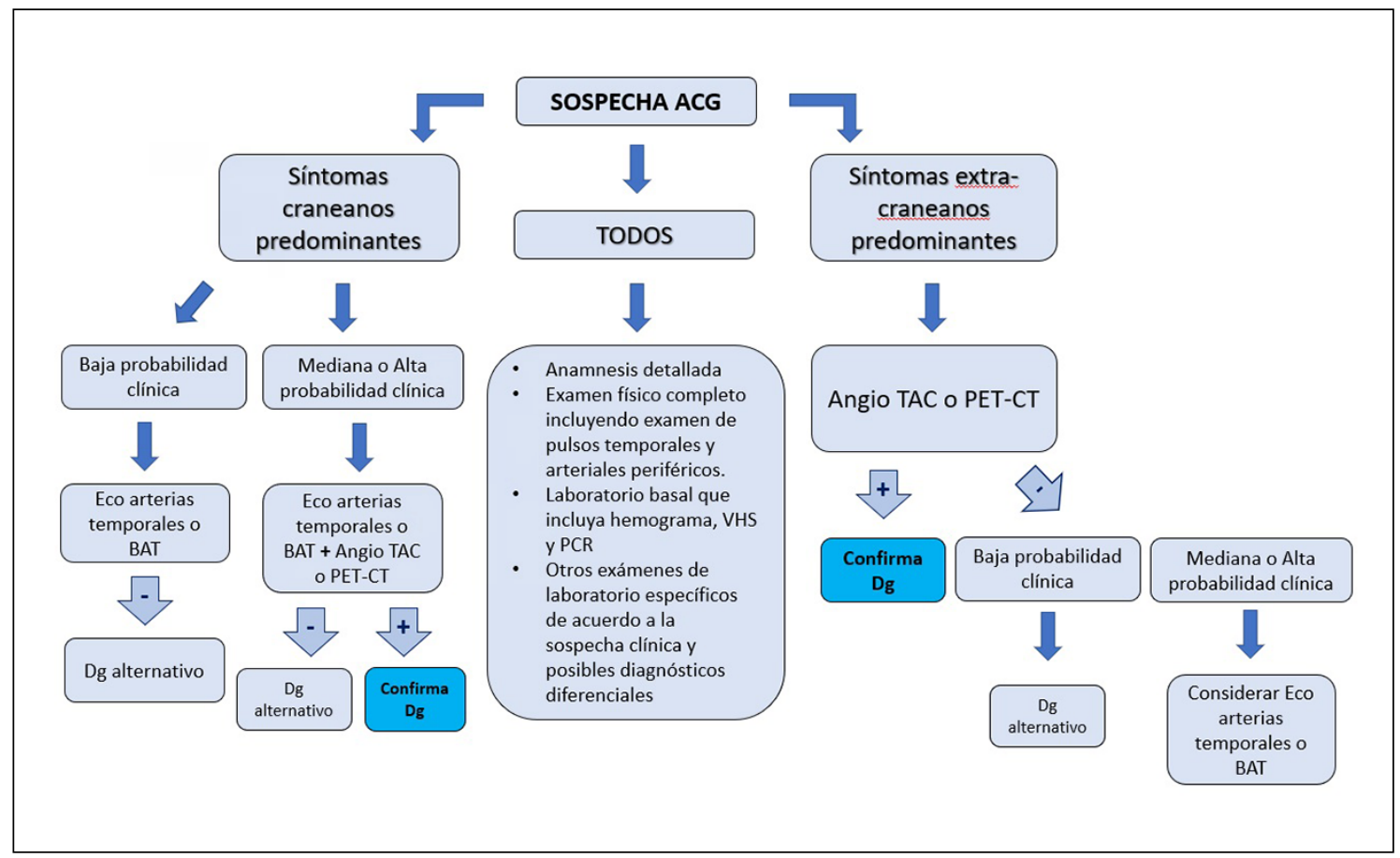

Figura 7. Algoritmo de estudio de ACG/PMR (modificado de Referencias 7, 34).

ACG de acuerdo al fenotipo principal de presentación $^{34,35}$, lo que obviamente debe ser adaptado a las condiciones locales de cada centro. En la Figura 7 se muestra una proposición de algoritmo diagnóstico que resume las opciones disponibles en la actualidad.

\section{Referencias}

1. Jennette J, Falk R, Bacon P, Basu N, Cid M, Ferrario F, et al. 2012 revised International Chapel Hill Consensus Conference Nomenclature of Vasculitides. Arthritis Rheum 2013; 65 (1): 1-11.

2. Lensen K, Voskuy A, Comans E, Laken Vd, Smulder Y. Extracranial giant cell arteritis: A narrative review. Neth J Med 2016; 74 (5):182-92.

3. Younger D. Giant Cell Arteritis. Neurol Clin 2019; 37 (2): 335-44.

4. Mahr A, Aouba A, Richebé P, Gonzalez-Chiappe S. Épidémiologie et histoire naturelle de l'artérite à cellules géantes (Horton). La revue de Médecine Interne 2017; 38 (10): 663-69.
5. Weyand C, Hicok K, Hunder G, Goronzy J. The HLADRB1 locus as a genetic component in giant cell arteritis. Mapping of a disease-linked sequence motif to the antigen binding site of the HLA-DR molecule. J Clin Invest 1992; 90 (6): 2355-61.

6. Dejaco C, Duftner C, Buttgereit F, Matteson E, Dasgupta $B$. The spectrum of giant cell arteritis and polymyalgia rheumatica: revisiting the concept of the disease. Rheumatology 2017; 56: 506-15.

7. Nuenninghoff D, Hunder G, Christianson T, McClelland R, Matteson E. Incidence and predictors of large-artery complication (aortic aneurysm, aortic dissection, and/or large-artery stenosis) in patients with giant cell arteritis: a population-based study over 50 years. Arthritis Rheum 2003; 48 (12): 3522-31.

8. Weyand C, Goronzy J. Clinical practice. Giant-cell arteritis and polymyalgia rheumatica. N Engl J Med 2014; 371 (1): 50-7.

9. Dejaco C, Ramiro S, Duftner C, Besson F, Bley T, Blockmans $\mathrm{D}$, et al. EULAR recommendations for the use of imaging in large vessel vasculitis in clinical practice. Ann Rheum Dis 2018; 77 (5): 636-43.

10. Hunder G, Bloch D, Michel B, Stevens M, Arend W, 
Calabrese L, et al. The American College of Rheumatology 1990. Criteria for the classification of Giant Cell Arteritis. Arthritis Rheum 1990; 33 (8): 1122-8.

11. Narváez J, Bernad B, Roig-Vilaseca D, García-Gómez C GVC, Juanola X. Influence of previous corticosteroid therapy on temporal artery biopsy yield in giant cell arteritis. Semin Arthritis Rheum 2007; 37 (1): 13-9.

12. Hellmich B, Agueda A, Monti S, Buttgereit F, De Boysson H, Brouwer E, et al. 2018 Update of the EULAR recommendations for the management of large vessel vasculitis. Ann Rheum Dis 2020; 79 (1): 19-30.

13. Karassa F, Matsagas M, Schmidt W, Ioannidis J. Meta-Analysis: Test Performance of Ultrasonography for Giant-Cell Arteritis. Ann Intern Med 2005; 142 (5): 359-69.

14. Luqmani R, Lee E, Singh S, Gillett M, Schmidt W, Bradburn M, et al. The Role of Ultrasound Compared to Biopsy of Temporal Arteries in the Diagnosis and Treatment of Giant Cell Arteritis (TABUL): a diagnostic accuracy and cost-effectiveness study. Health Technol Assess 2016; 20 (90): 1-238.

15. Czihal M, Zanker S, Rademacher A, Tatò F, Kuhlencordt $\mathrm{P}$, Schulze-Koops $\mathrm{H}$, et al. Sonographic and clinical pattern of extracranial and cranial giant cell arteritis. Scand J Rheumatol 2012; 41(3): 231-6.

16. Czihal M, Brendel T, Seibold C, Reincke M, Hoffmann U. Listen to the Axillary Artery Diagnosis of Occult Giant Cell Arteritis. J Clin Rheumatol 2011; 17 (4): 2145.

17. Nuenninghoff D, Hunder G, Christianson T, McClelland R, Matteson E. Incidence and predictors of large-artery complication (aortic aneurysm, aortic dissection, and/or large-artery stenosis) in patients with giant cell arteritis: a population-based study over 50 years. Arthritis Rheum 2003; 48 (12): 3522-31.

18. Schäfer V, Juche A, Ramiro S, Krause A, Schmidt W. Ultrasound cut-off values for intima-media thickness of temporal, facial and axillary arteries in giant cell arteritis. Rheumatology 2017; 56: 1479-83.

19. Monti S, Floris A, Ponte C, Schmidt W, Diamantopoulos A, Pereira C, et al. The use of ultrasound to assess giant cell arteritis: review of the current evidence and practical guide for the rheumatologist. Rheumatology 2018; 57: 227-35.

20. Duftner C, Dejaco C, Sepriano A, Falzon L, Schmidt W, Ramiro S. Imaging in diagnosis, outcome prediction and monitoring of large vessel vasculitis: a systematic literature review and meta-analysis informing the EULAR recommendations. RMD Open 2018; 4 (1): e000612. doi: 10.1136/rmdopen-2017-000612. eCollection 2018.
21. Karahaliou M, Vaiopoulos G, Papaspyrou S, Kanakis M, Revenas K, Sfikakis P. Colour duplex sonography of temporal arteries before decision for biopsy: a prospective study in 55 patients with suspected giant cell arteritis. Arthritis Res Ther 2006; 8 (4): 116.

22. Croft AP, Thompson N, Duddy MJ, Barton C, Khattak F, Molan SP et al. Cranial ultrasound for the diagnosis of giant cell arteritis. A retrospective cohort study. J R Coll Physicians Edinb 2015; 45: 268-72.

23. De Miguel E, Roxo A, Castillo C, Peiteado D, Villalba A, Martin-Mola E. The utility and sensitivity of colour Doppler ultrasound in monitoring changes in giant cell arteritis. Clin Exp Rheumatol 2012; 30 (70): S34-S38.

24. Hauenstein C, Reinhard M, Geiger J, Markl M, Hetzel A, Treszl A, et al. Effects of early corticosteroid treatment on magnetic resonance imaging and ultrasonography findings in giant cell arteritis. Rheumatology (Oxford) 2012; 51 (11): 1999-2003.

25. Germano G, Muratore F, Cimino L, Lo Gullo A, Possemato N, Macchioni P, et al. Is colour duplex sonography-guided temporal artery biopsy useful in the diagnosis of giant cell arteritis? A randomized study. Rheumatology (Oxford) 2015; 54 (3): 400-4.

26. Ball E, Walshm S, Tang T, Gohil R, Clarke J. Role of ultrasonography in the diagnosis of temporal arteritis. Br J Surg 2010; 97: 1765-71.

27. Lariviere D, Benali K, Coustet B, Pasi N, Hyafil F, Klein I, et al. Positron emission tomography and computed tomography angiography for the diagnosis of giant cell arteritis A real-life prospective study. Medicine (Baltimore) 2016; 95 (30): e4146. doi: 10.1097/ MD.0000000000004146.

28. Klink T, Geiger J, Both M, Ness T, Heinzelmann S, Reinhard $\mathrm{M}$, et al. Giant cell arteritis: diagnostic accuracy of MR imaging of superficial cranial arteries in initial diagnosis-results from a multicenter trial. Radiology 2014; 273 (3): 844-52.

29. Balink H, Bennink R, Van Eck-Smit B, Verberne $\mathrm{H}$. The Role of 18F-FDG PET/CT in Large-Vessel Vasculitis: Appropriateness of Current Classification Criteria? Biomed Res Int 2014; 2014: 687608. doi: 10.1155/2014/687608. Epub 2014 Aug 14.

30. Ernst D, Baerlecken N, Schmidt R, Witte T. Large vessel vasculitis and spondyloarthritis: coincidence or associated diseases? Scand J Rheumatol 2014; 43 (3): 246-8.

31. Rehak Z, Sprlakova-Pukova A, Kazda T, Fojtik Z, Vargova L, Nemec P. 18F-FDG PET/CT in polymyalgia rheumaticaa pictorial review. Br J Radiol 2017; 90 (1076): 20170198. doi: 10.1259/bjr.20170198. Epub 2017 Jun 16.

32. Yuge S, Nakatani K, Yoshino K, Koyama T. Diagnosing 
polymyalgia rheumatica on 18F-FDG PET/CT: typical uptake patterns. Ann Nucl Med 2018; 32: 573-7.

33. Hooisma G, Balink H, Houtman P, Slart R, Lensen K. Parameters related to a positive test result for FDG $\mathrm{PET}(/ \mathrm{CT})$ for large vessel vasculitis: a multicenter retrospective study. Clin Rheumatol 2012; 31:861-71.

34. Diamantopoulos A, Haugeberg G, Hetland H, Soldal D,
Bie R, Myklebust G. Diagnostic Value of Color Doppler Ultrasonography of Temporal Arteries and Large Vessels in Giant Cell Arteritis: A Consecutive Case Series. Arthritis Care Res (Hoboken) 2014; 66 (1): 113-9.

35. Koster M, Matteson E, Warrington K. Large-vessel giant cell arteritis: diagnosis, monitoring and management. Rheumatology (Oxford) 2018; 57(2): ii32-ii42. 